Zamorskii I., Unhuryan T., Batranovska S. The study of the prooxidant-antioxidant equilibrium in the kidney tissue and blood on the background of ceruloplasmin administration under the conditions of acute kidney injury. Journal of Education, Health and Sport. 2020;10(11):298-305. eISSN 2391-8306. DOI http://dx.doi.org/10.12775/JEHS.2020.10.11.030

https://apcz.umk.pl/czasopisma/index.php/JEHS/article/view/JEHS.2020.10.11.030

https://zenodo.org/record/4545781

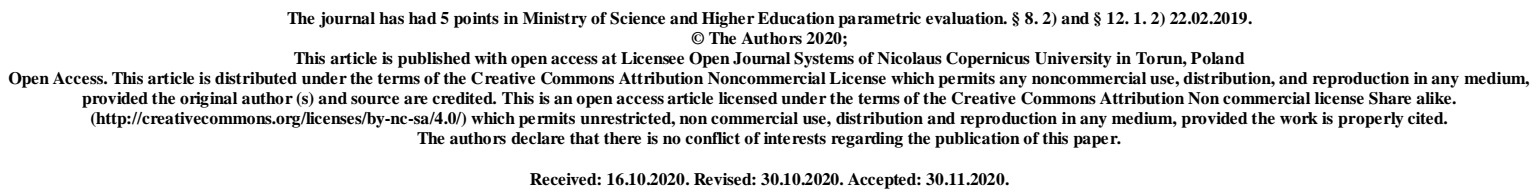

UDC: 615.36:615.275:616.61-002

\title{
THE STUDY OF THE PROOXIDANT-ANTIOXIDANT EQUILIBRIUM IN THE KIDNEY TISSUE AND BLOOD ON THE BACKGROUND OF CERULOPLASMIN ADMINISTRATION UNDER THE CONDITIONS OF ACUTE KIDNEY INJURY
}

\author{
I. Zamorskii, T. Unhuryan, S. Batranovska
}

\section{Bukovinian State Medical University}

\section{Abstract}

Acute kidney injury (AKI) remains a relevant medical problem. The promising direction of the AKI treatment is the use of the antioxidants that inhibit free radical processes and prevent the destruction of cell membranes within pathological processes. Ceruloplasmin (CP) is the main antioxidant of blood plasma, that demonstrates membrane protecting effects and antitoxic activity.

The aim of the study was to establish the influence of a single-dose administration of ceruloplasmin on the processes of the peroxidation in the kidney tissue and blood under the conditions of acute kidney injury.

Materials and methods. The influence of ceruloplasmin on the prooxidantantioxidant equilibrium in the kidney tissue and blood was studied in an experiment on white non-line rats under the conditions of rhabdomyolysis-induced acute kidney injury. The acute kidney injury was modeled by intramuscular administration of $50 \%$ glycerol solution at a dose of $8 \mathrm{mg} / \mathrm{kg}$. Ceruloplasmin was administered intraperitoneally at a dose of $7 \mathrm{mg} / \mathrm{kg} / \mathrm{day}$. 
The level of main indicators of prooxidant-antioxidant balance in blood and kidney tissue was determined in $24 \mathrm{~h}$ after glycerol administration for induction of acute kidney injury.

Research results and their discussion. There was a deep disruption of the prooxidant-antioxidant equilibrium as a result of the acute kidney injury. AKI causes an activation of the prooxidant processes by increasing the level of the malonic dialdehyde and the oxidized proteins in the kidney tissue and blood. AKI also reduces the antioxidant protection by decreasing the activity of the antioxidant enzymes in the kidneys and blood plasma.

A single-dose administration of ceruloplasmin improved antioxidant protection and reduced peroxidation of lipids and proteins. There was a decrease in levels of malondialdehyde and oxidative modification of proteins. At the same time, the antioxidant protection intensified due to an increase in the activity of glutathione peroxidase and catalase in the kidneys and blood plasma.

Conclusions. A single administration of ceruloplasmin influences prooxidantantioxidant balance, reducing the content of lipid and protein peroxidation products and increasing the activity of antioxidant enzymes.

\section{Key words: acute kidney injury; oxidative stress; prooxidant-antioxidant} balance; antioxidants; ceruloplasmin.

Introduction. The treatment and prevention of AKI remains a relevant problem, despite advances in modern medicine. The mortality of this pathology is $40-50 \%$, and if renal dysfunction reaches a degree of severity when renal substitution therapy is needed, the mortality rate increases to 60 per cent [7]. Thus, further study of nephroprotective agents is crucial.

One of the promising areas of AKI treatment are the antioxidants that inhibit free radical processes and prevent the destruction of cell membranes within the pathological processes. The pathogenesis of AKI is related with the peroxidation of lipids $[8,11,12,14]$, leading to imbalance among prooxidants and antioxidants, hence to the development of oxidative stress.

The formation of reactive oxygen species (ROS) in the organism can change the structure of DNA, leading to modification of proteins and lipids, activation of stress-induced transcription factors and production of pro-inflammatory and anti-inflammatory cytokines $[8$, 11]. The antioxidant defense mechanism of the organism encompasses enzymatic and nonenzymatic antioxidant, that can deactivate the free radicals [1-4]. 
Thereby, our attention was drawn to the antioxidant of blood plasma ceruloplasmin, that provides antioxidant protection. Its main physiological role is to participate in redox reactions, acting as a ferroxidase that oxidizes $\mathrm{Fe} 2+$ in $\mathrm{Fe} 3+$, that makes possible to include iron in transferrin without the formation of toxic products $[6,9,13]$. Ceruloplasmin manifests several kinds of the oxidase activity [5, 10], in particular, catalyzes oxidation of copper, promotes the oxidation of biogenic amines (norepinephrine, serotonin), actives NO-oxidase and superoxide dismutase, inhibits the prooxidant properties of myeloperoxidase. Ceruloplasmin demonstrates membranoprotective effects by normalizing the prooxidantantioxidant balance as a result of direct interaction with phospholipids of biological membranes [10].

Accordingly, these properties of ceruloplasmin evidence that it can prevent protein, DNA, and lipid damage. It also reduces endogenous intoxication and exhibits a radioprotective effect, stimulates hematopoiesis, immune processes and improves rheological properties of blood $[6,10,13]$. However, the data of an action of ceruloplasmin under the conditions of kidney damage is not enough.

The aim of the study. To detect the effects of the single-dose introduction of ceruloplasmin on the processes of peroxidation of lipids and proteins in kidney tissue and blood under the conditions of acute kidney injury.

Material and methods. The experimental studies were conducted on the white nonline laboratory rats weighing 160-250 g, which were kept in the standard vivarium conditions. The animals were divided into three groups. The first group consisted of the intact animals, the second one: the animals with AKI, that was caused on the background of intramuscular administration of $50 \%$ glycerol solution at a dose of $8 \mathrm{mg} / \mathrm{kg}$ [14]. The third group included the animals, which in 30 minutes after modeling of AKI was injected ceruloplasmin (Biopharma, Ukraine) at a dose of $7 \mathrm{mg} / \mathrm{kg}$ intraperitoneally. The euthanasia was performed in $24 \mathrm{~h}$ after administration of glycerol by decapitation under the light ether anesthesia, in accordance with the provisions of the European Convention for the protection of vertebrate animals used in experimental and other scientific purposes.

The state of prooxidant-antioxidant balance was estimated by the content of the malonic dialdehyde (MDA) and oxidatively modified proteins (OMP) in blood and kidney tissue, activity of the catalase and glutathione peroxidase in blood plasma and kidney tissue using standard biochemical methods [14].

Statistical processing of the obtained data was performed using the SPSS Statistics 17.0 software. All data are represented as a mean \pm standard error of the mean $(\mathrm{M} \pm \mathrm{m})$. 
Estimation of the differences between the samples was conducted using a parametric Student's t-test and a nonparametric Mann-Whitney $\mathrm{U}$ test. $\mathrm{P}<0,05$ was accepted as statistitically significant.

\section{Research results and discussion}

As a result of the AKI modeling, a deep disruption of the prooxidant-antioxidant balance, that occurs in the animals' organism, has been detected, which corresponds to the literature $[1,8,14]$.

The elevation of the peroxidation of lipids and proteins, characterized by a 1,6-fold increase of MDA in kidneys, as well as the OMP products, respectively, was revealed (Fig. 1, Fig. 2). There was also an increase of MDA by 1,8 and OMP by 1,6 -fold in blood. Inhibition of the antioxidant defense is observed, as evidenced by a 1.6-fold decrease in the activity of glutathione peroxidase (GP) in the kidneys and by a 1.8-fold in blood, as compared to intact animals. The activity of catalase (CAT) decreased by a 1,3-fold in blood and by a 1,4-fold in the kidneys (Fig. 3, Fig. 4).

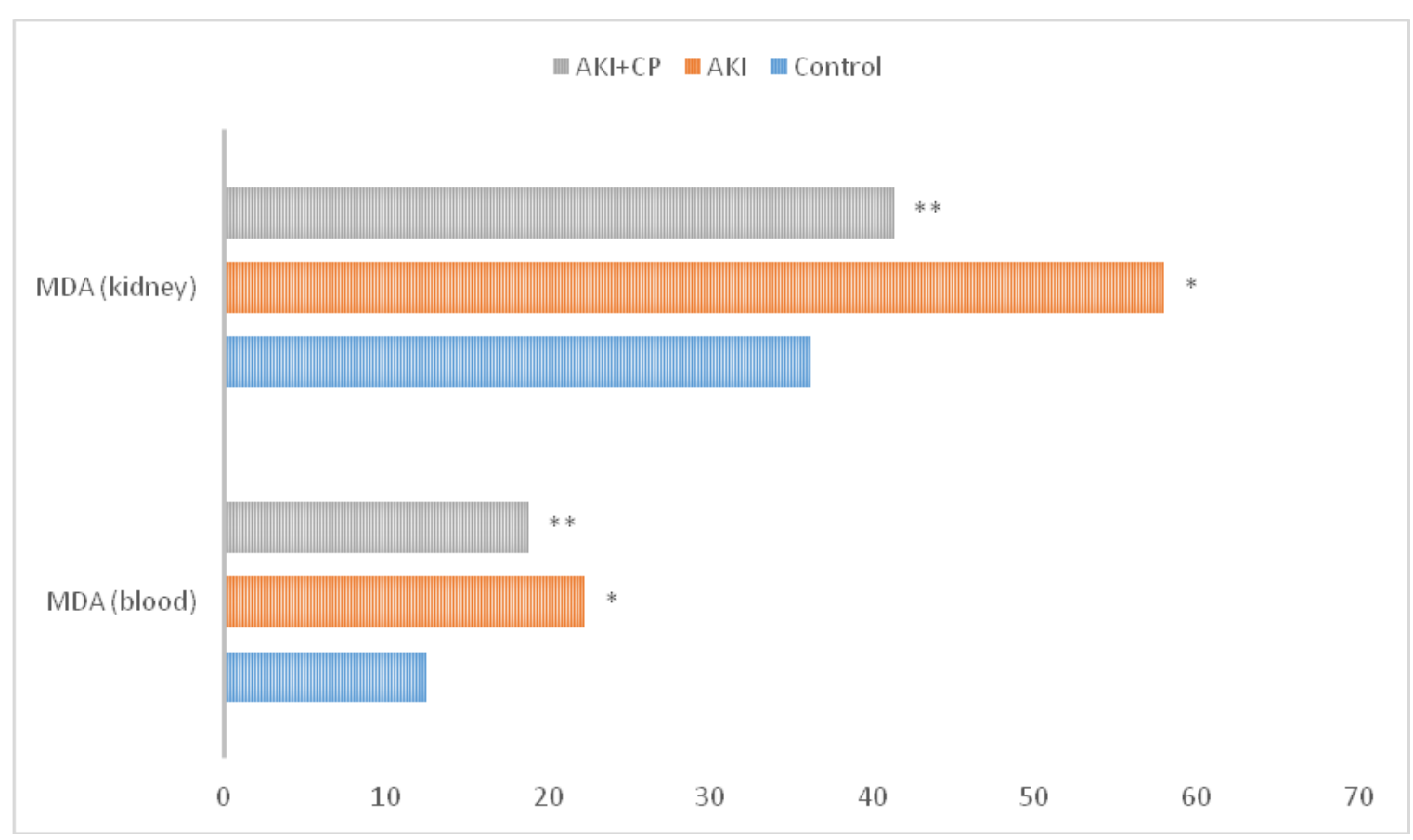

Fig 1. The level of malonic dialdehyde under the conditions of acute kidney injury

Note. Statistically significant differences: compared with the data of the group of intact control - * $(\mathrm{p}<0,01)$; compared with the data of the group of pathology (AKI) - ** (p $<0,01)$. MDA - malonic dialdehyde, CP - ceruloplasmin, AKI - acute kidney injury

A single administration of ceruloplasmin under the conditions of AKI was represented by improved antioxidant protection and reduced lipid and protein peroxidation products. 
Thus, a 1,4-fold and a 1,4-fold decrease of the MDA and OMB amount in the kidneys, respectively, was observed.

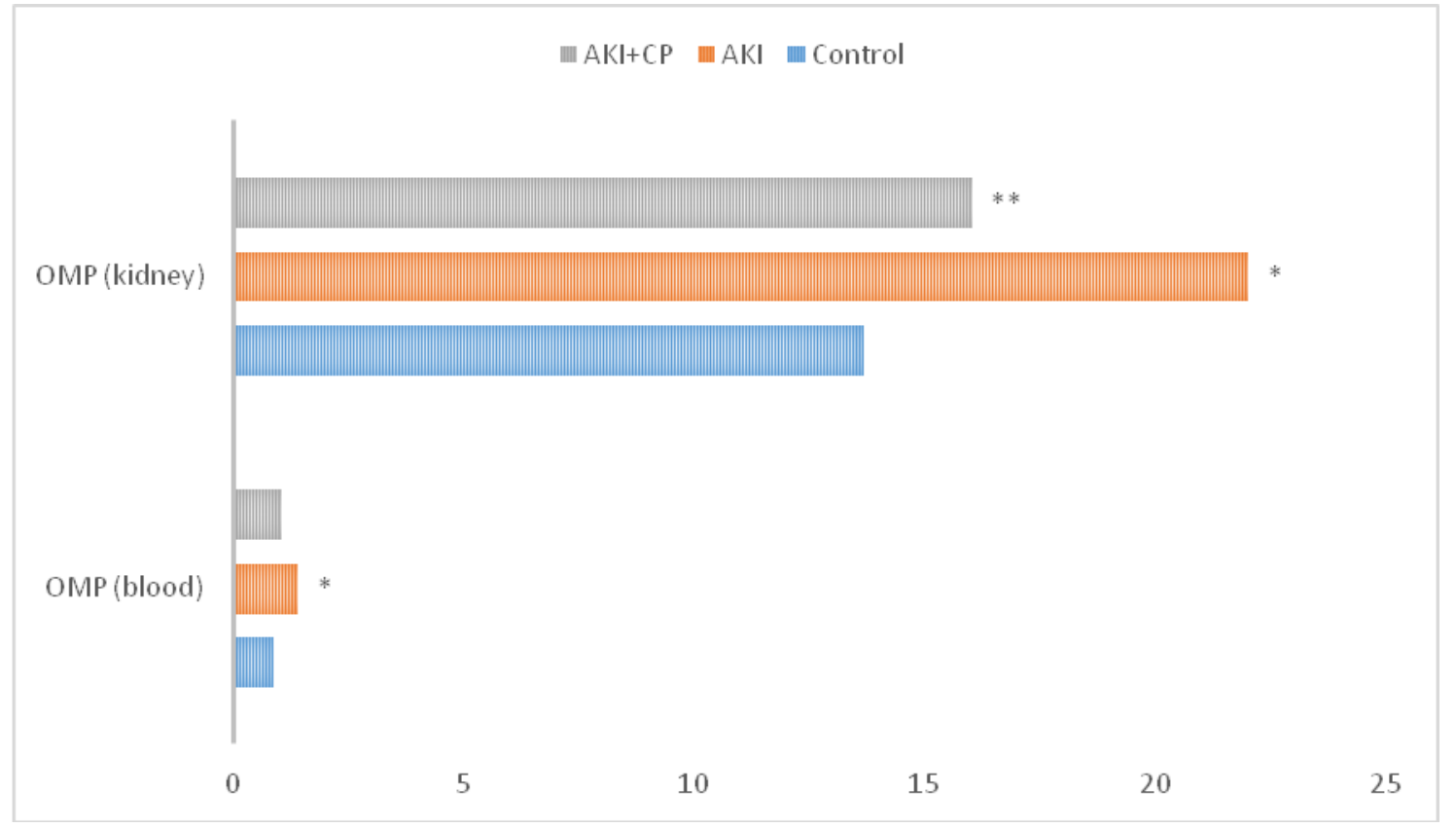
injury

Fig 2. The level of oxidatively modified proteins under the conditions of acute kidney

Note. Statistically significant differences: compared with the data of the group of intact control - * (p<0,01); compared with the data of the group of pathology (AKI) - ** (p $<0,01)$. OMP - oxidatively modified proteins, CP - ceruloplasmin, AKI - acute kidney injury

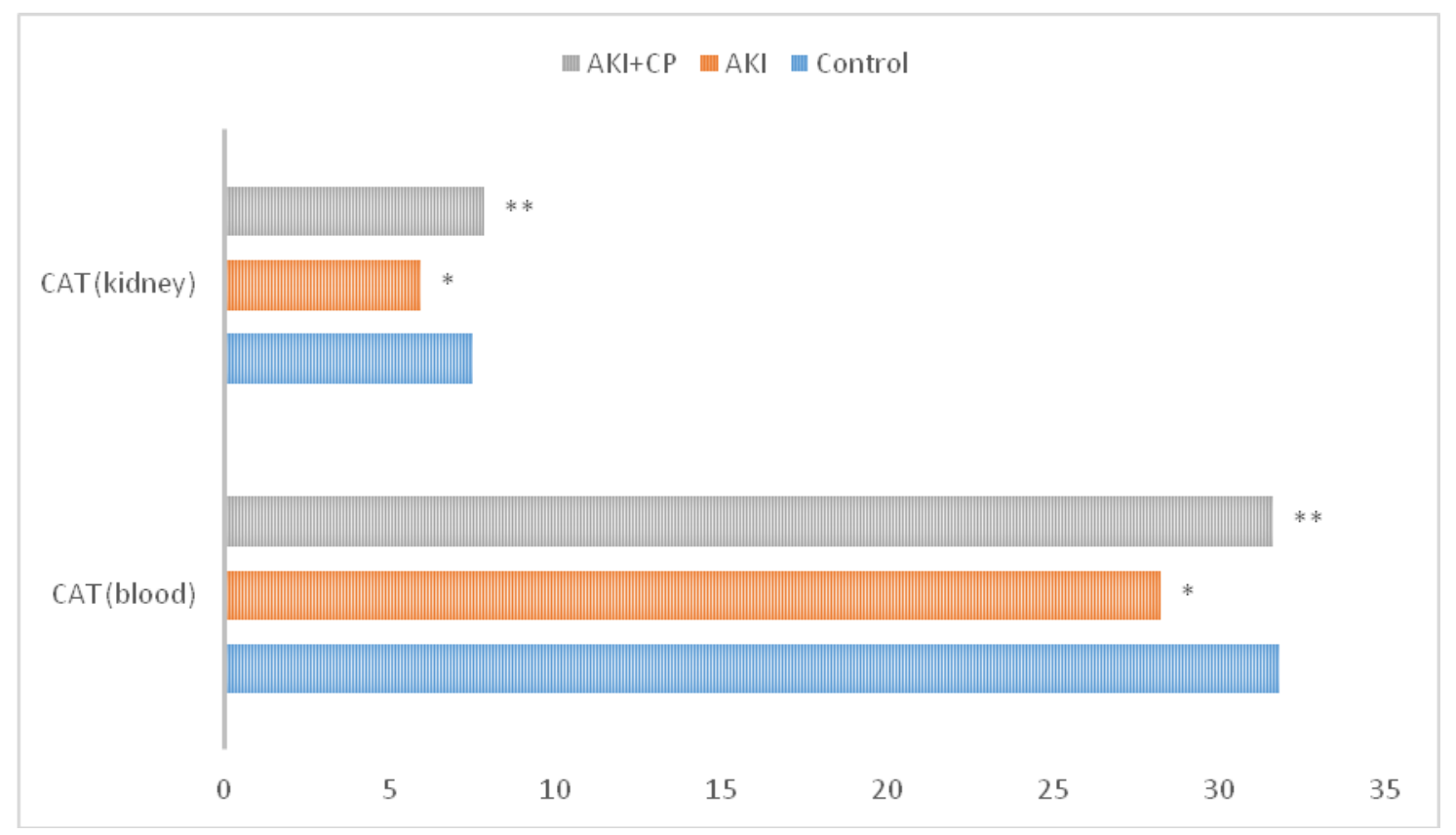

Fig 3. The activity of catalase under the conditions of acute kidney injury

Note. Statistically significant differences: compared with the data of the group of intact control - * ( $<<0,01)$; compared with the data of the group of pathology (AKI) - ** (p $<0,01)$. CAT - catalase, CP - ceruloplasmin, AKI - acute kidney injury 


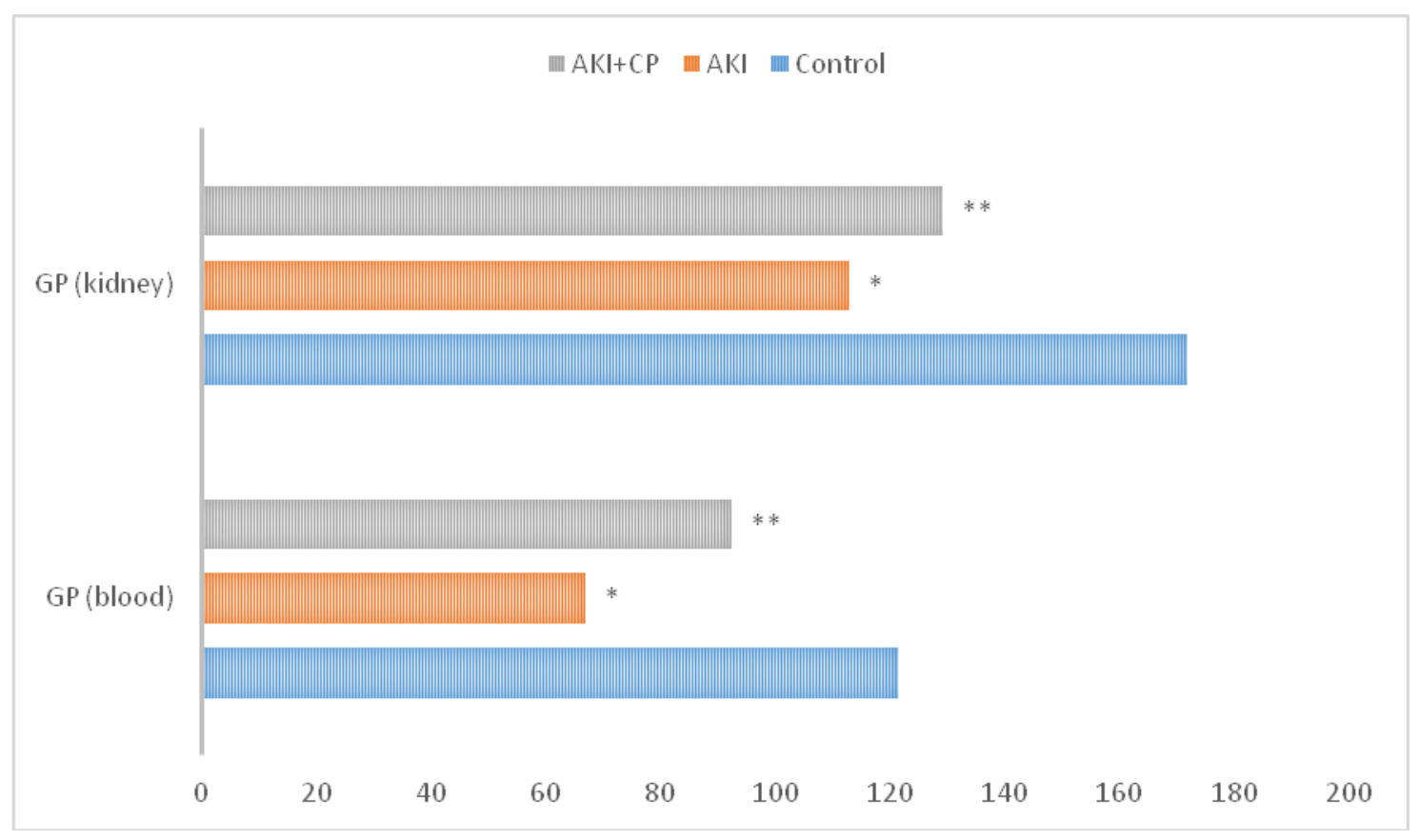
injury

Fig 4. The activity of glutathione peroxidase under the conditions of acute kidney

Note. Statistically significant differences: compared with the data of the group of intact control - * $(\mathrm{p}<0,01)$; compared with the data of the group of pathology (AKI) - ** (p $<0,01)$. GP - glutathione peroxidase, CP - ceruloplasmin, AKI - acute kidney injury

At the same, the level of MDA decrease by a 1,3-fold in blood, also the level of OMP decrease by a 1,4-fold. Simultaneously, antioxidant defense was enhanced by a 1,2-fold and a 1,3-fold increase of GP and catalase activity in the kidneys, respectively, and a 1,2-fold increase of CAT level in blood plasma, as compared with the group of pathology. The activity of glutathione peroxidase on the background of ceruloplasmin administration increase by a 1,4-fold.

Consequently, based on the findings of the study, it can be noted that the use of a natural antioxidant of blood plasma, ceruloplasmin, under the conditions of experimental AKI diminished the violation of the prooxidant-antioxidant equilibrium in animals.

\section{Conclusions}

The activation of prooxidant processes under the conditions of acute kidney injury, occurs due to increase of the content of malonic dialdehyde and oxidatively modified proteins in kidney tissue and blood, as well as the inhibition of activity of antioxidant enzymes.

A single administration of ceruloplasmin in a dose of $7 \mathrm{mg} / \mathrm{kg}$ under the conditions of acute kidney injury leads to the restoration of prooxidant-antioxidant equilibrium, reducing the content of lipid and protein peroxidation products and rising the activity of antioxidant enzymes. 


\section{References}

1. Birben E, Sahiner U.M., Sackesen C., Erzurum S., Kalayci O. (2012) Oxidative stress and antioxidant defense. WAO Journal, 5, 10-19.

2. Dennis J. M., Witting P. K. (2017) Protective Role for Antioxidants in Acute Kidney Disease. Nutrients., 9, 718. P.25. www.mdpi.com/journal/nutrients

3. Elshama S., Abdalla M.E., Mohamed A.M. (2018) Role of Natural Antioxidants in Treatment of Toxicity. Journal of Toxicological Analysis, 1, 3

4. Hasanuzzaman M., Bhuyan M.H.M.B., Zulfiqar F., Raza A., Mohsin S.M., Mahmud J.A., Fujita M., Fotopoulos V. (2020) Reactive Oxygen Species and Antioxidant Defense in Plants under Abiotic Stress: Revisiting the Crucial Role of a Universal Defense Regulator. Antioxidants, 9, 681; doi:10.3390/antiox9080681

5. Golenkina E.A., Viryasova G.M., Galkina S.I., Gaponova T.V., Sud'ina G.F., Sokolov A.V. (2018) Fine Regulation of Neutrophil Oxidative Status and Apoptosis by Ceruloplasmin and Its Derivatives. Cells. 7, 8. doi:10.3390/cells7010008 www.mdpi.com/journal/cells

6. Linder M.C. (2016) Ceruloplasmin and Other Copper Binding Components of Blood Plasma and Their Functions: An Update. Metallomics, 1-37. doi: 10.1039/C6MT00103C.

7. Makris K., Spanou L. (2016) Acute Kidney Injury: Definition, Pathophysiology and Clinical Phenotypes. The Clinical Biochemist, 37 (2), 85-98.

8. Palipoch S. (2013) A review of oxidative stress in acute kidney injury: protective role of medicinal plants-derived antioxidants. Afr. J. Tradit Complement Altern Med., 10 (4), 88-93.

9. Ramos D., Mar D., Ishida M., Vargas R., Gaite M., Montgomery A. et al. (2016) Mechanism of Copper Uptake from Blood Plasma Ceruloplasmin by Mammalian Cells. PLoS ONE, 11(3), e0149516. doi: 10.1371/journal.pone.0149516

10. Samygina V.R., Sokolov A.V., Bourenkov G., Petoukhov M.V., Pulina M.O., Zakharova E.T, et al. (2013) Ceruloplasmin: Macromolecular Assemblies with Iron Containing Acute Phase Proteins. Plos one, 7(8), 1-12.

11. Tamay-Cacha F., Quintana-Pereza J. C., Trujillo-Ferraraa J. G., CuevasHernandeza R.I., Del Valle-Mondragonb L., Garcia-Trejoc E. M., Arellano-Mendoza M.G. (2016) A review of the impact of oxidative stress and some antioxidant therapies on renal damage. Renal failure, 38 (2), 171-175. doi.org/10.3109/0886022X.2015.1120097 
12. Tsai W.H., Huang S.T., Liu W.C., Chen LW, et al. (2015) High risk of rhabdomyolysis and acute kidney injury after traumatic limb compartment syndrome. Ann Plast Surg. 74, 2, 158-61.

13. Vashchenko G., MacGillivray R.T.A. (2013) Multi-copper oxidases and human iron metabolism. Nutrients, 5, 2313-25.

14. Zamorskii I.I., Drachuk V.M., Horoshko O.M. (2016) The nephroprotective effects of taurine in acute kidney injury due to rhabdomyolysis. Biophysics, 6 (61), 1036-38. 